\title{
Best practice guidelines for molecular analysis in spinal muscular atrophy $\dagger$
}

\author{
Hans Scheffer ${ }^{\star},{ }^{1}$ Jan Maarten Cobben ${ }^{2}$, Gert Matthijs ${ }^{3}$ and Brunhilde Wirth ${ }^{4}$
}

${ }^{1}$ Department of Medical Genetics, University of Groningen, The Netherlands; ${ }^{2}$ Department of Clinical Genetics, Free University Hospital Amsterdam, The Netherlands; ${ }^{3}$ Center for Human Genetics, University of Leuven, Belgium; ${ }^{4}$ Institute of Human Genetics, University of Bonn, Germany

With a prevalence of approximately $1 / 10000$, and a carrier frequency of $1 / 40-1 / 60$ the proximal spinal muscular atrophies (SMAs) are among the most frequent autosomal recessive hereditary disorders. Patients can be classified clinically into four groups: acute, intermediate, mild, and adult (SMA types I, II, III, and IV, respectively). The complexity and instability of the genomic region at chromosome $5 q 13$ harbouring the disease-causing survival motor neuron 1 (SMN1) gene hamper molecular diagnosis in SMA. In addition, affected individuals with SMA-like phenotypes not caused by SMN1, and asymptomatic individuals with two mutant alleles exist. The SMN gene is present in at least one telomeric (SMN1) and one centromeric copy (SMN2) per chromosome in normal (non-carrier) individuals, although chromosomes containing more copies of SMN1 and/or SMN2 exist. Moreover, the two SMN genes (SMN1 and SMN2) are highly homologous and contain only five base-pair differences within their $3^{\prime}$ ends. Also, a relatively high de novo frequency is present in SMA. Guidelines for molecular analysis in diagnostic applications, carrier detection, and prenatal analysis using direct and indirect approaches are described. Overviews of materials used in the molecular diagnosis as well as Internet resources are included. European Journal of Human Genetics (2001) 9, 484-491

Keywords: SMA; molecular analysis; guidelines; SMN

\section{Description of the disease}

The spinal muscular atrophies are a clinically and genetically heterogeneous group of neuromuscular disorders caused by degeneration of anterior horn cells. In proximal spinal muscular atrophy (SMA), the muscles of the extremities closest to the trunk are more severely and earlier affected. SMA is clinically classified into four types: acute, intermediate, mild, and adult (SMA types I, II, III, and IV, respectively). ${ }^{1,2}$ Used nomenclature is summarised in Table 1. Criteria for clinical classification of SMA I, II, and III patients are summarised in Table 2. ${ }^{49}$ With an estimated

\footnotetext{
*Correspondence: H Scheffer, Department of Medical Genetics, University of Groningen, Antonius Deusinglaan 4, NL-9713 AW Groningen, The Netherlands.

Tel: +3150 3632925; Fax: +3150 3632947;

E-mail: h.scheffer@medgen.azg.nl

$\dagger$ These guidelines are the result of a best practice meeting funded by the European Molecular Genetics Quality Network (EMQN) in Groningen, The Netherlands on 21 September 2000. A list of participants is presented in Appendix 1.

Received 17 January 2001; revised 22 March 2001; accepted 13 April 2001
}

incidence of $\sim 1 / 10000,3,4,46-48$ and a carrier frequency of $1 / 40-1 / 60^{5,6}$ the SMAs are among the most frequent autosomal recessive hereditary disorders, and apparently the incidence is similar in different populations studied. The SMA 5q13 region shows a complex structure at the genomic level, including a 500-kilobase pair duplication and inversion. ${ }^{7}$ The survival of motor neuron (SMN) gene exists as two homologues, at least one telomeric gene (SMN1) and in the vast majority of chromosomes at least one centromeric gene (SMN2) per chromosome in normal (non-carrier) individuals, although also chromosomes with an intact SMN1 gene exist that lack SMN2. ${ }^{7}$ The two SMN genes (SMN1 and SMN2) are highly homologous and contain only five base-pair differences that occur within their $3{ }^{\prime}$ regions. ${ }^{8}$ These differences in exons 7 and 8 are used to distinguish SMN1 and SMN2 in DNA analysis. Deletions of the SMN1 gene appear to be directly involved in SMA, ${ }^{7}$ since exon(s) 7 (and 8) of SMN1 are undetectable in over 95\% of patients, irrespective of their clinical type, , $^{-12,14}$ either as a result of homozygous deletions, or because of conversion of sequences of SMN1 into those of the SMN2 gene. ${ }^{7,11-16}$ The 
Table 1 Nomenclature and gene ID in SMA

\begin{tabular}{|c|c|c|c|}
\hline OMIM No & OMIM name & Gene name & $G D B I D$ \\
\hline 253300 & $\begin{array}{c}\text { Spinal muscular } \\
\text { atrophy I; (SMA 1, } \\
\text { Werdnig-Hoffmann } \\
\text { disease) }\end{array}$ & & \\
\hline 253550 & $\begin{array}{l}\text { Spinal muscular } \\
\text { atrophy II; (SMA 2) }\end{array}$ & & \\
\hline 253400 & $\begin{array}{c}\text { Spinal muscular } \\
\text { atrophy III; (SMA 3; } \\
\text { Kugelberg-Welander } \\
\text { disease) }\end{array}$ & & \\
\hline \multirow[t]{2}{*}{ *600354 } & & $\begin{array}{c}\text { Survival of Motor } \\
\text { Neuron 1, } \\
\text { telomeric }\end{array}$ & $\begin{array}{l}\text { GDB:120378 } \\
\text { (Gene) }\end{array}$ \\
\hline & & $(\mathrm{SMN} 1)$ & $\begin{array}{l}\text { GDB: } 4405727 \\
\text { (Syndromic } \\
\text { region) }\end{array}$ \\
\hline
\end{tabular}

Table 2 Criteria for clinical classification of SMA patients

\begin{tabular}{lccc}
\hline $\begin{array}{l}\text { Clinical } \\
\text { subtype }\end{array}$ & $\begin{array}{c}\text { Age of onset } \\
\text { (in months) }\end{array}$ & $\begin{array}{c}\text { Motor } \\
\text { milestones }\end{array}$ & $\begin{array}{c}\text { Death } \\
\text { (in years) }\end{array}$ \\
\hline SMA type I & $<6$ & Never sit unaided & $<2$ \\
SMA type II & $<18$ & Never walk unaided & $>2$ \\
SMA type III & $>18$ & Stand unaided & adult \\
\hline
\end{tabular}

A SMA type IV has been described by Pearn ${ }^{3}$. In this subtype the clinical symptoms start after the age of 30 years in the majority of cases.

identification of several small mutations in the SMN1 gene in patients without a deleted or sequence-converted SMN1 allele ${ }^{7,17-25,29}$ provide strong evidence that the SMN1 gene is the primary SMA-determining gene. The clinical phenotype of SMA appears to be partly determined by the underlying mutational mechanism. Most cases of SMA type I result from homozygous gene-deletion events, whereas the milder forms of the disease, SMA types II and III, are more likely to result from gene conversion of SMN1 into SMN2; SMA type II from a gene conversion event in one allele in addition to a hemizygous deletion event in the other allele; in SMA type III from gene conversions in both alleles. ${ }^{7,13,15,16,26,27}$ As a result, patients suffering from the milder forms of SMA carry more copies of the SMN2 gene. In the Smn1-/-SMN2 mouse models, multiple copies of human SMN2 seem to prevent SMA development in Smn1-deleted animals (almost) completely. ${ }^{38,39}$ The absence of SMN1 exon 7 in SMA patients can be used as a diagnostic tool for SMA, ${ }^{7,28}$ with a sensitivity of approximately $95 \%$ in clinically strictly defined SMA patients in most populations. Most available assays are not quantitative, however. Based on Hardy-Weinberg equilibrium, the remaining patients (SMA patients without a homozygous SMN1 deletion) are virtually all assumed to have a hemizygous SMN1 absence of at least exon 7, either by deletion or by conversion. Several papers including those by
Table 3 Guidelines for the clinical indications for DNA analysis

\begin{tabular}{ll}
\hline Clinical presentation & Test \\
\hline $\begin{array}{l}\text { Any reasonable suspicion } \\
\text { of SMA }\end{array}$ & $\begin{array}{c}\text { Homozygous SMN1 exon 7 } \\
\text { deletion test } \\
\text { Clinical criteria supporting the } \\
\text { diagnosis of SMA types I, } \\
\text { II, or III should be in }\end{array}$ \\
$\begin{array}{l}\text { agreement with those } \\
\text { described, }\end{array}{ }^{40}$ including \\
characteristic abnormalities \\
in a muscle biopsy
\end{tabular}

McAndrew et al, ${ }^{21}$ Wirth et al, ${ }^{29}$ Gerard et al ${ }^{41}$ and Scheffer et $a l^{30}$ have described quantitative assays based on competitive amplification of SMN1 and SMN2 exon 7 to determine their gene-copy number.

\section{Common reasons for referral}

Confirmation of the clinical diagnosis or suspicion of SMA by the detection of homozygous SMN1 exons 7 and exon 8 deletions is fast, inexpensive, and reliable. The clinical sensitivity is around 95\%, the clinical specificity is over 99\%. Therefore, no restricting clinical criteria are warranted before undertaking DNA analysis. This is certainly so in neonatal cases in which a rapid molecular analysis and diagnosis may render more invasive procedures (ie, a muscle biopsy) unnecessary. A different situation exists when hemizygous SMN1 deletion analysis or subtle mutation analysis is asked for. Our guidelines are summarised in Table 3.

Other reasons for referral include carrier detection by direct hemizygous SMN1 exon 7 deletion analysis and/or indirect linkage analysis. Carrier detection by direct analysis is indicated in siblings and close relatives of SMA patients with a homozyous SMN1 exons 7 and 8 deletion, in parents of SMA patients who died, and in partners of ascertained carriers without positive family history for SMA. Indirect analysis can only be applied in family members of a patient, assuming that an adequate number of family members are available for analysis to establish linkage phase. Direct analysis is strongly recommended in these cases.

A third indication for DNA analysis is prenatal analysis. This is often requested by parents of a SMA patient, and may also be indicated for couples who have been shown to be carriers of a mutant SMN1 allele, or for couples of an affected patient with SMA with an identified carrier, which is not a rare situation in SMA type III.

\section{Approaches}

General strategy

1 Appropriate patients selected for molecular analysis.

2 Confirmation of clinical diagnosis by analysis of homozygous SMN1 exon 7 deletion. 
3 Before embarking on hemizygous SMN1 deletion analysis in cases without homozygous deletion, additional clinical information including muscle biopsy is requested according to criteria summarised in Table 3.

4 Heterozygous deletion analysis by dosimetric SMN1 exon 7 test. If a patient, fulfilling the clinical criteria of SMA, is found heterozygous, there is a $95 \%$ chance that (s)he will be compound heterozygous for a deletion and a (subtle) mutation (see below).

5 Subtle mutation analysis (optional; see below).

6 Carrier detection by dosimetric SMN1 exon 7 test and/or linkage analysis in relatives. Prior to dosimetric analysis in relatives testing of parents of the homozygously SMN1 deleted index case is strongly recommended (cf. section SMN1 Exon 7 Dosage Analysis and Carrier Testing).

7 Carrier testing in partners of ascertained carriers by dosimetric SMN1 exon 7 test.

8 Prenatal analysis by homozygous SMN1 exon 7 deletion analysis or by a combination of (subtle) mutation analysis and linkage analysis. Some laboratories confirm the results by linkage analysis using markers flanking SMN1. Exclusion by microsatellite analysis of an interfering degree of admixture of maternal cells in the foetal tissue is obligatory.

\section{Confirmation of clinical diagnosis}

The ability to detect deletions in SMN1 means that testing to confirm a diagnosis of SMA in affected individuals is possible. The presence of a homozygous deletion of exons 7 and 8 is consistent with a diagnosis of SMA given that there are clinical grounds for suspecting SMA. The absence of a homozygous SMN1 deletion does not rule out a diagnosis of SMA since approximately $6 \%$ of cases are known not to have a homozygous SMN1 deletion, a proportion of those SMA patients will have a subtle mutation in one or extremely rarely in both SMN1 alleles instead. ${ }^{45}$ In routine SMN1 testing, a DNA-laboratory often has no or only scarce clinical data on a given patient. In that case, whenever a homozygous SMN1 deletion is not found in a patient, one should doubt the diagnosis of SMA. The presence of a hemizygous SMN1 exon 7 deletion identified by a quantitative determination of the number of SMN1 exon 7 copies may provide further support for the diagnosis of SMA (appr. 95-96\% of SMA patients have at least a heterozygous SMN1 deletion). Nevertheless, formal confirmation of the clinical diagnosis in those cases can only be obtained after identification of subtle SMN1 mutation(s).

The clinical subtype of SMA appears to be determined (in part) by the nature of the SMN1 mutations. In general, SMA type I is associated with deletions in both alleles, SMA type 2 with a deletion in one, and a gene conversion in the other allele, and SMA type 3 with gene conversions in both alleles. The molecular identification of absence of exon 7 in both alleles of SMN1 in the presence of one or two copies of SMN1 exon 8 is indicative for such gene conversions. However, these data, when available, can at present not be used to predict the clinical course of the disease.

\section{Carrier testing}

Several papers including those by McAndrew et al, ${ }^{21}$ Wirth et $a l,{ }^{29}$ Gerard et $a l^{41}$ and Scheffer et $a l^{30}$ have described quantitative assays based on competitive amplification of SMN1 and SMN2 exons 7 to determine their gene-copy number. These techniques have now been implemented in a number of service labs for carrier detection.

SMN1 de novo deletions occur at a frequency of approximately $2 \%$ of SMA patients, the majority being of paternal origin. ${ }^{6,32}$ Testing of parents of homozygously deleted SMA patients may give additional information on de novo deletions. It has been shown in the majority of cases that these de novo deletions are associated with a meiotic recombination or meiotic gene conversion. Hence the recurrence risk in such particular families would theoretically not be elevated. However, Campbell et al ${ }^{50}$ reported on possible germinal mosaicism in SMA, which would lead to an elevated recurrence risk. In practice, these data should lead to prenatal diagnosis despite evidence of a de novo mutation.

A complication/pitfall in the dosimetric analysis of SMN1 exon 7 is the occurrence of two (or more) SMN1 genes on a single chromosome 5 in about 4\%, as observed by McAndrew et $a l^{21}$ Wirth et $a l^{35}$ and others. This would bear on the sensitivity of this technique for carrier identification, since individuals with an SMN1 [1,1] genotype (a single SMN1 gene on each chromosome; non-carriers) cannot be distinguished from individuals with an SMN1 $[0,2]$ genotype (both SMN1 genes on a single chromosome; carriers). Also, in carrier testing of individuals without a positive family history for SMA, eg, testing of partners of known carriers, it should be taken into account that mutant non-deletion SMN1 alleles (approximately $2.5 \%$ of mutant SMN1 alleles) will not be detected. The consequences for the sensitivity and specificity of carrier testing by a dosimetric method have been discussed. ${ }^{29,30}$

Since the frequency of carriers with two SMN1 genes per chromosome is $4 \%$, compared to only $1 \%$ of parents being non-carrier due to a de novo mutation, no direct conclusions should be drawn from apparently normal results in carrier testing in parents of affected individuals. This problem can be resolved by the identification of a recombination event associated with the de novo mutation by indirect analysis, eg, by using the multicopy markers Ag1-CA and $\mathrm{C} 212^{32}$ or other flanking markers. Alternatively, the occurrence of a de novo deletion can be confirmed by normal SMN1 dosage in the parents of the apparent non-carrier parent, ie, two of the grandparents of the affected child. When two SMN1 genes on a single chromosome (opposite to a chromosome lacking an intact SMN1 gene) cause the normal SMN1 dosage in the carrier parent, one grandparent will have an SMN1 dosage compatible with a single SMN1 gene. The other grandparent will have an SMN1 dosage compatible with three SMN1 
genes. When the normal dosage in the parent is caused by a de novo mutational event in the affected child, both grandparents will have normal SMN1 dosage.

Quantitative SMN1 exon 7 analysis should be restricted to families in which a homozygous SMN1 deletion has been identified in the index case, in order to prevent performing dosage analysis in relatives of patients with a SMA type phenotype not caused by SMN1. An exception could be made in parents of a deceased patient with a clinically quite clear diagnosis of SMA.

Carrier testing in relatives of SMA patients, eg, siblings and/ or uncles and aunts could also be performed by indirect analysis using flanking markers. A prerequisite is the availability of sufficient DNA samples from family members for establishing linkage phase and informativity of the markers.

\section{Prenatal testing}

Prenatal analysis is carried out preferably by direct mutation detection, eg, by testing for a homozygous SMN1 exon 7 deletion. A prerequisite is the identification of a homozygous deletion in the index patient.

Homozygous deletions of SMN1 exons 7 and 8 in unaffected haplo-identical sibs of SMA patients have been described. ${ }^{10,11,31}$ Parents of a SMA patient may actually have a homozygous SMN1 deletion themselves. Although it is hard to predict whether the parental SMN1 deletion allele that had not been transmitted to the affected child may have a pathogenic effect at all, it is our opinion that it cannot be considered simply as a non-risk SMN1 allele. Such an allele should be dealt with as an allele with a potential pathogenic effect.

Prenatal testing based on linkage analysis is useful in families with a clinically ascertained patient with proximal SMA without a homozygous SMN1 deletion. It is recommended that this approach should only be used when a hemizygous SMN1 deletion has been identified in the index case. An exception could be made in special cases with a clinically quite clear diagnosis of SMA and consanguinity of the parents, making homozygosity for a rare nondeletion mutant SMN1 allele in the index case more likely. Prenatal analysis in families with non-deleted patients should generally not be performed. Flanking markers may also be used to confirm the results of deletion analysis in prenatal testing, and to exclude interfering admixture of maternal cells in the foetal sample. Some laboratories prefer the use of markers from other chromosomes for exclusion of maternal admixture from foetal tissue to circumvent unwanted information about the foetal carrier status.

\section{Linkage analysis}

Linkage analysis is useful for carrier testing if quantitative deletion analysis is not feasible.

In postnatal applications, linkage-based testing of unaffected siblings, or preferably the grand-parents of the index case, may be useful to identify a possible meiotic recombination associated with a de novo deletion or rearrangement involving SMN1. Also, uniparental isodisomy may be identified by the use of flanking markers.

Some laboratories have the policy to include unaffected siblings in a linkage analysis only when necessary, in order to avoid problems with the identification of carriers in young children. However, this depends on the local situation.

\section{Technical protocols}

\section{Analysis of homozygous SMN1 deletions}

Homozygous deletions of exons 7 and 8 of SMN1 can be detected by several methods including:

1 SSCP - either on polyacrylamide ( $8 \%$ on $12 \mathrm{~cm}$ gels works well) or MDE gels. ${ }^{7}$ Primer sequences and PCR conditions are summarised in the section 'Primer Sequences'. The deletion can be visualised by silver staining of the gels as well as by radioactivity or fluorescence. ${ }^{42}$ SSCP has the advantage that subtle mutations in the gene may be detected as well as deletions. However, the method will also identify neutral polymorphisms. A study from Wang et $a l^{31}$ has shown that $4 \%$ of asymptomatic family members carry a polymorphic variant of exon 7 of SMN1 (telomeric) which looks like a homozygous deletion on SSCP gels.

2 Restriction enzyme digestion. ${ }^{28,29}$ For exon 7 the enzymes DraI or Hinfl could be used to separate SMN1 and SMN2 in combination with specific primers, for exon $8 \mathrm{DdeI}$ can be used. Primer sequences and PCR conditions are summarised in the section 'Primer sequences'. These are rapid assays, and have the additional advantage that the pathogenic absence of SMN1 exons 7 and 8 is very specifically tested for.

Gene conversion can be detected by SSCP analysis, dependent on local laboratory conditions used. The restriction digest method does not differentiate between a true deletion and a gene conversion, but correctly determines absence of SMN1 exons 7 and 8 from their normal genomic position.

Some laboratories prefer to confirm exon 7 only deletions by a second, independent test (in the majority of cases absence of both exons 7 and 8 is detected; these test results confirm each other). Testing for SMN1 exon 7 is the most accurate test, and some laboratories consider testing for SMN1 exon 8 being redundant. Testing for SMN1 exon 8 only may lead to a false negative result.

It is recommended that samples from patients known to have a homozygous SMN1 deletion (positive reference samples) as well as samples known to contain intact SMN1 allele(s) (negative reference samples) are always digested and run in parallel on gels to monitor completeness of the 
digestion, in addition to a no template control reaction to exclude carry-over contamination.

\section{Dosage analysis of hemizygous SMN1 deletions}

A number of quantitative assays based on competitive amplification of SMN1 and SMN2 exons 7 to determine their gene-copy number have been described. ${ }^{21,29,30,42}$ Primer sequences and PCR conditions are summarised in the section 'Primer Sequences'. Technical details and pitfalls can be found in the original papers by McAndrew et $a l^{21}$ Wirth et al, ${ }^{29}$ Gerard et al $^{41}$ and Scheffer et al. ${ }^{30}$ The latter system makes use of fluorescently labelled primers, enabling the analysis to be performed on an automated sequencer. Reference samples with known SMN1 exon 7 copy number should be included on the gels. These assays make use of internal standard plasmids that are added to the reaction mixture for monitoring of the efficiency of the amplification. For availability of these standards and internal controls, the corresponding authors of the respective papers should be contacted.

New PCR technology, eg, based on real time PCR (eg, Taqman or FRET technologies), allows the quantification of the PCR during the course of the reaction. Applications for SMA are currently under development.

Since in clinical DNA service practice the majority of the tests used are currently based on qualitative analyses, it is strongly recommended that implementation of a quantitative SMN1 assay should be preceded by a thorough validation of sensitivity and specificity by the laboratory wishing to undertake this testing.

\section{Linkage analysis}

A number of informative microsatellite markers flanking the SMA gene are summarised in Table $4 .^{33-37}$ It should be possible to find an informative proximal and distal marker in the majority of cases so that the overall error based on linkage with flanking markers is $<1 \%$.

There are also multi-copy markers including C212 and C272 (Ag1-CA), which lie near the $5^{\prime}$ end of SMN1. ${ }^{6,43,44}$ These can also be used although the interpretation of alleles requires considerable experience.

\section{SMN1 subtle mutation analysis}

SMN1 subtle mutation analysis is beyond the scope of current routine DNA service for SMA. In cases where analysis of subtle mutations is necessary, laboratories offering this facility (eg, Bonn, Groningen) should be contacted. In these cases, the clinical diagnosis should meet the criteria formulated in Table 3.

\section{Primer sequences}

The primer sequences are taken from the references indicated. Individuals should consult the appropriate reference for full instructions and information on primer use. While every effort has been made to ensure the accuracy of
Table 4 Genetic markers flanking the SMN1 gene at 5q11.2-q13.3

\begin{tabular}{lcccc}
\hline Locus & Location & Recombination & PIC & Size \\
\hline D5S679 & Proximal & 3 & 0.63 & $180-222$ \\
D5S680 & Proximal & 3 & 0.57 & $141-173$ \\
D5S125 & Proximal & 2 & 0.38 & 143 and 147 \\
D5S681 & Proximal & 2 & 0.68 & $142-156$ \\
D5S435 & Proximal & 1 & 0.68 & $128-144$ \\
D5S629 & Proximal & 1 & 0.81 & $233-253$ \\
D5S823 & Proximal & 1 & 0.54 & $128-150$ \\
D5S1556/ & Intragenic/SMN1 & 0 & 0.98 & $90-122$ \\
D5F150 & promoter region & & & \\
D5S149 & Intragenic/SMN1 & 0 & 0.99 & $166-203$ \\
& promoter region & & & \\
D5S557 & Distal & 1 & 0.46 & $148-172$ \\
D5S610 & Distal & 1 & 0.80 & $106-124$ \\
D5S351 & Distal & 1 & 0.74 & $196-234$ \\
5'-MAP1B & Distal & 1 & 0.76 & $\sim 100$ \\
3'-MAP1B & Distal & 1 & 0.72 & $212-226$ \\
D5S112 & Distal & 3 & 0.74 & $94-120$ \\
D5S127 & Distal & 5 & 0.84 & $96-114$ \\
D5S39 & Distal & 7 & 0.74 & $212-220$ \\
\hline Primer sequences & PCR Conditions & etc. & & \\
\hline
\end{tabular}

Primer sequences, PCR conditions, etc. can be found in the Genome Database (http://gdbwww.gdb.org).

the primer sequences, individual users should confirm these sequences before use.

SMN1/2 exon 7 and exon 8 amplification for SSCP Lefebvre et $\mathrm{al}^{7}$ Exon 7: R111: 5'-AGACTATCAACTTAATTTCTGATCA-3' 541C770: 5'-TAAGGAATGTGAGCACCTTCCTTC-3' (Modified by Matthijs et al. ${ }^{42}$ into SMA7B: 5'TCCTTAATTTAAGGAATGTGAGCA-3'); Exon 8: 541C960: 5'-GTAATAACCAAATGCAATGTGAA-3'; 541C1120: 5'-CTACAACACCCTTCTCACAG-3'

SMN1/2 exon 7 homozygous deletion tests using restriction enzymes DraI or HinfI

Van der Steege et al $^{28} \quad \mathrm{R} 111$ is used as forward primer. X7Dra: 5'-CCTTCCTTCTTTTTGATTTTGTTT-3'; DraI will cleave SMN2 exon 7 specifically.

Wirth et al ${ }^{29}$ SMN7F: 5'-CTTCCTTTTATTTTCCTTACAGGGATT-3'; SMN7R: 5'-TCCACAAACCATAAAGTTTTAC-3'; The SMN1 exon 7 product will contain two HinfI sites; the SMN2 exon 7 product will contain one HinfI site.

SMN1 exon 8 homozygous deletion test using DdeI $541 \mathrm{C} 960$ and 541C1120 are used as forward and reverse primers, respectively. DdeI will cleave SMN2 exon 8 specifically.

SMN1 exon 7 dosage analysis

McAndrew et al ${ }^{21}$ R111 and X7-Dra are used as forward and reverse primers, respectively. The reference PCR product from the CFTR gene is amplified using CF621F: 5'-AGTCACCAAAGCAGTACAGC-3' as forward primer, and CF621R: 5'- 
GGGCCTGTGCAAGGAAGTGTTA-3' as reverse primer. For monitoring the efficiency of the PCR, cloned DNA of a SMN and a CFTR internal standard are added to the multiplex reaction.

Wirth et al $^{29}$ SMN7F and SMN7R are used as forward and reverse primers, respectively. The reference PCR product is amplified using CF621F and CF621R. For monitoring the efficiency of the PCR, cloned DNA of a SMN and a CFTR internal standard are added to the multiplex reaction.

Scheffer et al $^{30}$ R111 (fluorescently labelled) and X7-Dra are used as forward and reverse primers, respectively. The reference product from the RB1 gene is amplified using Rbex13F: 5'-ATTACACAGTATCCTCGACA-3'; RBex13R (fluorescently labelled): 5'-TATACGAACTGGAAAGATGC-3'. For monitoring the efficiency of the PCR, cloned DNA of a SMN and an RB1 internal standard are added to the multiplex reaction.

\section{Internet resources}

http://www3.ncbi.nlm.nih.gov/htbin-post/Omim/dispmim?600354 (OMIM entry for SMN1)

http://www3.ncbi.nlm.nih.gov/htbin-post/Omim/dispmim?253300 (OMIM entry for SMA1)

http://www3.ncbi.nlm.nih.gov/htbin-post/Omim/dispmim?253550 (OMIM entry for SMA2)

http://www3.ncbi.nlm.nih.gov/htbin-post/Omim/dispmim?253400 (OMIM entry for SMA3)

http://bioinfo.weizmann.ac.il/cards-bin/cardsearch.pl?search=SMA (Genecards for SMA and SMN1 and SMN2)

http://gdbwww.gdb.org/gdb-bin/genera/genera/hgd/Gene?!key=GDB\%3A120378\&!sub=0 (SMA entry in Genome Database)

ftp://ftp.genethon.fr/pub/Gmap/Nature-1995/data/data_chrom5 (Genethon genetic map of chromosome 5)

http://www.ncbi.nlm.nih.gov/genemap/map.cgi?$\mathrm{MAP}=\mathrm{GB} 4 \& \mathrm{BIN}=180 \& \mathrm{MARK}=2660$ (Genemap 99 section including SMN1)

http://www.ncbi.nlm.nih.gov/entrez/query.fcgi?CMD=search\&DB=PubMed (PubMed search page)

http://archive.uwcm.ac.uk/uwcm/mg/search/ 5215173.html (Human Gene Mutation Database entry for SMN1)

http://www.neuro.wustl.edu/neuromuscular/synmot.html\#sma5q

\section{Appendix 1}

Participants EMQN SMA Best Practice Meeting (2000) Groningen, The Netherlands

Vesa Juvonen, University of Turku, Department of Medical Genetics, Kiinamyllynkatu 10, FIN-20520 Turku, Finland E-mail: vesa.juvonen@utu.fi
Rosario dos Santos, Instituto de Genética Médica Jacinto d, Praça Pedro Nunes 74, P-4000 Porto, Portugal

E-mail: rosario.santos@igm.min-saude.pt

Elaine Robertson, Kennedy Galton Centre, North West London Hospitals NHS Trust, Waterford Road, Harrow HA1 3UJ, United Kingdom

E-mail: s.j.payne@ic.ac.uk

Alessandra Tacconelli, Università degli Studi di Roma Tor Vergata, Dipartemento di Biopatologica e Diagnostica per Immagini, Edificio E Nord pt. Terra, Via di Tor Vergata 135, I-00133 ROMA, Italy

E-mail: Novelli@med.uniroma2.it

Maggie Williams, Southmead Hospital, Molecular Genetics Unit, Bristol, BS10 5NB, United Kingdom

E-mail: williamsmag@yahoo.com

Gert Matthijs, Katholieke Universiteit Leuven, Centre for Human Genetics, Gasthuisberg ON 6, Herestraat 49, B-3000 Leuven, Belgium E-mail: Gert.Matthijs@med.kuleuven.ac.be

Francine Thonney, Genetique Medicale, CHUV, 1011 Lausanne, Switzerland

E-mail: Francine.thonney@hospvd.ch

Kyproula Christodoulou, The Cyprus Institute of Neurology and Genetics, 6 International Airport Ave, PO Box 23462, 1683 Nicosia, Cyprus

E-mail: Roula@mdrtc.cing.ac.cy

Hiljar Sibul, Tartu University, Molecular Diagnostics Centre, United Laboratories, Oru 3 St. 51005 Tartu, Estonia E-mail: Hsibul@ebc.ee

Marianne Schwartz, Department of Clinical Genetics, Rigshopitalet 4062, Blegdamsvej 9, DK-2100, Copenhagen, Denmark

E-mail: Schwartz@rh.dk

Eva Bjorck, Sahlgrenska University Hospital, Department of Clinical Genetics, Pital-East, 41685 Gothenburg, Sweden E-mail: Eva.bjorck@obgyn.se

Veronika Karcagi, Dept of Biochemistry, National Institute of Environmental Health, Gyali u. 2-6, 1097 Budapest, Hungary

E-mail: Karcagi@oki1.joboki.hu

Vickey Lindley, Birmingham Women's Hospital, Regional Genetics Service, DNA Laboratory, Edgbaston, Birmingham, B15 2TH, United Kingdom

E-mail: fiona.macdonald@bham-womens.thenhs.com

Aileen Butler, National Center for Medical Genetics, Our Lady's Hospital for Sick Children, Crumlin, Dublin 12, Ireland

E-mail: aileen.butler@olhsc.ie

Gerhard Meng, Institut fur Humangenetik, Biozentrum, AmHubland, D97074 Wuerzburg, Germany E-mail: gmeng@biozentrum.uni-wuerzburg.de

Sara Seneca, Vrije Universiteit Brussel, Dienst Medische Genetica VUB, Laarbeeklaan 101, B-1090 Bruxelles, Belgium

E-mail: lgensas@az.vub.ac.be 
Willy Lissens, Vrije Universiteit Brussel, Dienst Medische Genetica VUB, Laarbeeklaan 101, B-1090 Bruxelles, Belgium

E-mail: lgenlsw@az.vub.ac.be

André Reeber, CNRS INSERM Université Louis Pasteur,

Diagnostic Genetique, 11 Rue Humann, F-67085 Strasbourg

Cedex, France

E-mail: areeb@igbmc.u-strasbg.fr

Mireille Cossee, CNRS INSERM Université Louis Pasteur,

Diagnostic Genetique, 11 Rue Humann, F-67085

Strasbourg Cedex, France

E-mail: cossee@igbmc.u-strasbg.fr

Kiriaki Kekoy, Dept of Medical Genetics, Athens University,

'Aghia Sophia' Children's Hospital, Athens, Greece

E-mail: kkekou@cc.uoa.gr

Angela Apessos, Alfa lab, Medical Institute of Research and

Diagnosis S.A., 8, Anastasiou str., 11525 Athens, Greece

E-mail: angelaa@hol.gr

Jan Maarten Cobben, Academisch Ziekenhuis Vrije

Universiteit, De Boelelaan 1117, 1081 HV Amsterdam,

The Netherlands

E-mail: JM.Cobben@azvu.nl

Marianne de Visser, Academisch Medisch Centrum, Meibergdreef 9, 1105 AZ Amsterdam, The Netherlands

E-mail: M.deVisser@amc.uva.nl

Brunhilde Wirth, Institute of Human Genetics, Univ. of

Bonn, Wilhelmstrasse 31, 53111 Bonn, Germany

E-mail: bwirth@uni-bonn.de

Su Stenhouse, Northern Regional Genetics Service, 19/20 Claremont Place, Newcastle upon Tyne

NE2 4AA, United Kingdom

E-mail: s.a.r.stenhouse@ncl.ac.uk

Hans Scheffer, Dept. of Medical Genetics, Univ. of

Groningen, Antonius Deusinglaan 4, 9713 AW Groningen,

The Netherlands

E-mail: h.scheffer@medgen.azg.nl

\section{Acknowledgments}

We thank Prof Charles HCM Buys and Dr Robert MW Hofstra for critical reading and valuable contributions to the discussion paper prior to the meeting, and all participants of the best practice meeting for their suggestions and additions.

\section{References}

1 Emery AE: The nosology of spinal muscular atrophies. J Med Genet 1971; 8: 481-495.

2 Dubowitz V: Muscle disorders in childhood. Philadelphia, Saunders Co, 1978.

3 Thieme A, Mitulla B, Schulze F, Spiegler AW: Epidemiological data on Werdnig-Hoffmann disease in Germany (West-Thuringen). Hum Genet 1993; 91: 295 - 297.

4 Thieme A, Mitulla B, Schulze F, Spiegler AW: Chronic childhood spinal muscular atrophy in Germany (West-Thuringen)-an epidemiological study. Hum Genet 1994; 93: 344-346.
5 Pearn J: Classification of spinal muscular atrophies. Lancet 1980 i: $919-922$.

6 Melki J, Lefebvre S, Bürglen, L et al: De novo and inherited deletions of the $5 \mathrm{q} 13$ region in spinal muscular atrophies. Science 1994; 264: 1474-1477.

7 Lefebvre S, Bürglen L, Reboullet $S$ et al: Identification and characterization of a spinal muscular atrophy-determining gene. Cell 1995; 80: $155-165$.

8 Bürglen L, Lefebvre S, Clermont $\mathrm{O}$ et al: Structure and organization of the human survival motor neurone (SMN) gene. Genomics 1996; 32: 479-482.

9 Bussaglia E, Clermont O, Tizzano E et al: A frameshift deletion in the survival motor neuron gene in Spanish spinal muscular atrophy patients. Nature Genet 1995; 11: $335-337$.

10 Cobben JM, van der Steege G, Grootscholten P, de Visser M, Scheffer H, Buys CHCM. Deletions of the survival motor neuron gene in unaffected siblings of patients with spinal muscular atrophy. Am J Hum Genet 1995; 57: 805-808.

11 Hahnen E, Forkert R, Marke C et al: Molecular analysis of candidate genes on chromosome $5 \mathrm{q} 13$ in autosomal recessive spinal muscular atrophy: evidence of homozygous deletions of the SMN gene in unaffected individuals. Hum Molec Genet 1995; 4: $1927-1933$.

12 Velasco E, Valero C, Valero A, Moreno F, Hernandez-Chico C: Molecular analysis of the SMN and NAIP genes in Spanish spinal muscular atrophy (SMA) families and correlation between number of copies of cBCD541 and SMA phenotype. Hum Mol Genet 1996; 5: 257-263.

13 Hahnen E, Schonling J, Rudnik-Schoneborn S, Zerres K, Wirth B: Hybrid survival motor neuron genes in patients with autosomal recessive spinal muscular atrophy: new insights into molecular mechanisms responsible for the disease. Am J Hum Genet 1996; 59: $1057-1065$

14 Rodrigues NR, Owen N, Talbot K, Ignatius J, Dubowitz V, Davies KE: Deletions in the survival motor neuron gene on $5 \mathrm{q} 13$ in autosomal recessive spinal muscular atrophy. Hum Mol Genet 1995; 4: 631-634.

15 van der Steege G, Grootscholten PM, Cobben JM et al: Apparent gene conversions involving the SMN gene in the region of the spinal muscular atrophy locus on chromosome 5. Am J Hum Genet 1996; 59: 834-838.

16 DiDonato CJ, Chen X-N, Noya D, Korenberg JR, Nadeau JH, Simard LR: Cloning, characterization, and copy number of the murine survival motor neuron gene: homolog of the spinal muscular atrophy-determining gene. Genome Res 1997; 7: $339-$ 352.

17 Brahe C, Clermont O, Zappata S, Tiziano F, Melki J, Neri G: Frameshift mutation in the survival motor neuron gene in a severe case of SMA type I. Hum Mol Genet 1996; 5: 1971-1976.

18 Bürglen L, Seroz T, Miniou P et al: The gene encoding p44, a subunit of the transcription factor TFIIH, is involved in largescale deletions associated with Werdnig-Hoffmann disease. Am J Hum Genet 1997; 60: 72 - 79

19 Parsons DW, McAndrew PE, Monani UR, Mendell JR, Burghes WHM, Prior TW: An 11 base pair duplication in exon 6 of the SMN gene produces a type I spinal muscular atrophy (SMA) phenotype: further evidence for SMN as the primary SMAdetermining gene. Hum Mol Genet 1996; 5: 1727-1732.

20 Hahnen E, Schonling J, Rudnik-Schoneborn S, Zerres K, Wirth B: Missense mutations in exon 6 of the survival motor neuron gene in patients with spinal muscular atrophy. Hum Mol Genet 1997; 6: $821-825$

21 McAndrew PE, Parsons DW, Simard LR et al: Identification of proximal spinal muscular atrophy carriers and patients by analysis of SMNT and SMNC gene copy number. Am J Hum Genet 1997; 60: 1411-1422.

22 Rochette CF, Surh LC, Ray PN et al: Molecular diagnosis of nondeletion SMA patients using quantitative PCR of SMN exon 7. Neurogenetics 1997; 1: 1: 141-147. 
23 Talbot K, Ponting PC, Theodosiou AM et al: Missense mutation clustering in the survival motor neuron gene: a role for a conserved tyrosine and glycine rich region of the protein in RNA metabolism? Hum Mol Genet 1997; 6: 497-500.

24 Parsons DW, McAndrew PE, Allison PS, Parker Jr WD, Burghes WHM, Prior TW: Diagnosis of spinal muscular atrophy in an SMN non-deletion patient using a quantitative PCR screen and mutation analysis. J Med Genet 1998; 35: 674-676.

25 Wang CH, Papendick BD, Bruinsma P, Day JK: Identification of a novel missense mutation of the SMNt gene in two siblings with spinal muscular atrophy. Neurogenetics 1998; 1: 273-276.

26 Burghes AHM: When is a deletion not a deletion? When it is converted. Am J Hum Genet 1997; 61: 9-15.

27 Campbell L, Potter A, Ignatius J, Dubowitz V, Davies K: Genomic variation and gene conversion in spinal muscular atrophy: implications for disease process and clinical phenotype. Am J Hum Genet 1997; 61: 40-50.

28 van der Steege G, Grootscholten PM, van der Vlies P et al: PCRbased DNA test to confirm clinical diagnosis of autosomal recessive spinal muscular atrophy [letter]. Lancet 1995; 345: $985-986$.

29 Wirth B, Herz M, Wetter A et al: Quantitative analysis of Survival Motor Neuron Copies: Identification of Subtle SMN1 Mutations in Patients with Spinal Muscular Atrophy, Genotype-Phenotype Correlation, and Implications for Genetic Counseling. Am J Hum Genet 1999; 64: 1340-1356.

30 Scheffer H, Cobben JM, Mensink RGJ, Stulp RP, van der Steege G, Buys CHCM: SMA carrier detection: Validation of hemizygous SMN exon 7 deletion test for the identification of proximal spinal muscular atrophy carriers and patients with a single allele deletion. Eur J Hum Genet 2000; 8: 79-86.

31 Wang $\mathrm{CH}, \mathrm{Xu} \mathrm{Y}$, Carter TA et al: Characterisation of survival motor neuron (SMNT) gene deletions in asymptomatic carriers of spinal muscular atrophy. Hum Mol Genet 1996; 5: 359-365.

32 Wirth B, Schmidt T, Hahnen E et al: De novo rearrangements found in $2 \%$ of index patients with spinal muscular atrophy: mutational mechanisms, parental origin, mutation rate, and implications for genetic counseling. Am J Hum Genet 1997; 61 $1102-1111$

33 Daniels et al: Prenatal prediction of spinal muscular atrophy. J Med Genet 1992; 29: $165-170$.

34 Morrison et al: Two novel microsatellite markers for prenatal prediction of spinal muscular atrophy. Hum Genet 1993; 92: $133-138$.

35 Wirth et al: Large linkage analysis in 100 families with autosomal recessive spinal muscular atrophy (SMA) and 11 CEPH families using 15 polymorphic loci in the region $5 q 11.2$ q13.3. Genomics 1994; 20: 84-93.
36 Burghes et al: Linkage mapping of the spinal muscular atrophy gene. Hum Genet 1994; 93: 305-312.

37 Brahe et al: Mapping of two new markers within the smallest interval harboring the spinal muscular atrophy locus by family and radiation hybrid analysis. Hum Genet 1994; 93: 494-501.

38 Monani UR, Sendtner M, Coovert DD et al: The human centromeric survival motor neuron gene (SMN2) rescues embryonic lethality in $\operatorname{Smn}(-/-)$ mice and results in a mouse with spinal muscular atrophy. Hum Mol Genet 2000; 9: 333-339.

39 Hsieh-Li HM, Chang JG, Jong YJ et al: A mouse model for spinal muscular atrophy. Nat Genet 2000; 24: 66-70.

40 Munsat TL, Davies KE: Meeting report: International SMA Consortium Meeting. Neuromuscul Disord 1992; 2: 423-428.

41 Gerard B, Ginet N, Matthijs G et al: Genotype determination at the survival motor neuron locus in a normal population and SMA carriers using competitive PCR and primer extension. Hum Mutat 2000; 16: 253-263.

42 Matthijs G, Schollen E, Legius E et al: Unususal molecular findings in autosomal recessive spinal muscular atrophy. J Med Genet 1996; 33: $469-474$.

43 DiDonato C, Morgan K, Carpten JD et al: Association between Ag1-CA alleles and severity of autosomal recessive proximal spinal muscular atrophy. Am J Hum Genet 1994; 55: 1218 - 1229.

44 Wirth B, Hahnen E, Morgan $\mathrm{K}$ et al: Allelic association and deletions in autosomal recessive proximal spinal muscular atrophy. Association of marker genotype with disease severity and candidate cDNAs. Hum Mol Genet; 4: 1273-1284.

45 Wirth B: An update of the mutation spectrum of the survival motor neuron gene (SMN1) in autosomal recessive spinal muscular atrophy (SMA). Hum Mutat 2000; 15: 228-237.

46 Pearn J: The gene frequency of acute Werdnig-Hoffmann disease (SMA type I). A total population survey in North-East England. J Med Genet 1973; 10: 260-265.

47 Pearn J: Incidence, prevalence and gene frequency of chronic childhood spinal muscular atrophy. J Med Genet 1978; 15: 409 413.

48 Czeizel A, Hamula J: A Hungarian study on Werdnig-Hoffmann disease. J Med Genet 1989; 26: $761-763$.

49 Munsat TL: Workshop report-International SMA collaboration. Neuromusc Disord 1991; 1: 81.

50 Campbell L, Daniels RJ, Dubowitz V, Davies KE: Maternal mosaicism for a second mutational event in a type I spinal muscular atrophy family. Am J Human Genet 1998; 63: $37-44$. 